\title{
A DIALECTICAL CONSTRUCTIVIST VIEW OF THE CREATION OF PERSONAL MEANING
}

\author{
LESLIE S. GREENBERG and JUAN PASCUAL-LEONE \\ Department of Psychology, York University, Toronto, Ontario, Canada
}

\begin{abstract}
A dialectical constructivist approach, based on a theory of constructive operators (TCO), is presented. This theory explains human psychological functioning as produced by dynamic syntheses of a variety of schemes, the "software," and mental "hardware" operators. In this model the activity of the subject is captured by means of such mental operations as allocation of attention to, or interruption of the application of schemes, as well as by executive processing. These all influence the probability of certain schemes being activated and synthesized in a field of internal complexity. Using this theory as a base, the process of meaning construction in therapy is described as a dialectical synthesis between two major types of processing, conceptual and experiential. These act together to constantly generate explanations of experience. Three important moments in the construction process, emotional arousal, symbolization, and reflection are discussed. Finally a therapy transcript is analyzed in terms of the TCO to illustrate the dynamic syntheses and mental operations involved in generating meaning in therapy.
\end{abstract}

In a dialectical-constructivist view (Greenberg \& Pascual-Leone, 1995; Greenberg, Rice, \& Elliott, 1993; Pascual-Leone 1978, 1980, 1983, 1987, 1990a, 1990b, 1991; Watson \& Greenberg, 1996), conscious personal meaning is seen as being generated by cognitive processes that construct different selves at different times (Hermans, Kempen, \& van Loon, 1992). These processes do so, however, by drawing on a variety of sources and levels of information, the most important of which is affective experience. Emotion is seen as serving an organizing role in human experience and is crucial in the creation of personal meaning. It is part of an ongoing dialectic between two major streams of consciousness: Consciously-mediated conceptualization that provides explanation, and automatic, immediate emotional experience that provides sensorimotor experience (Gendlin, 1962, 1964, 1968; Greenberg

Received 12 July 2000; accepted 31 October 2000.

Address correspondence to Leslie S. Greenberg, Department of Psychology, York University, 4700 Keele St., Toronto, Ontario, Canada M3J 1P3. E-mail: lgrnberg@yorku.ca 
\& Safran, 1987; Greenberg, Rice, \& Elliott, 1993; Guidano, 1987, 1991, 1995; Mahoney, 1991).

In this article, we will present a summary of Pascual-Leone's theory of constructive operators (TCO), which serves as the foundation of a dialectical constructivist view of mental functioning. In this more abstract and complex aspect of this article, different levels and modes of processing will be discussed in order to demonstrate how a constructive system might operate. This will be followed by a more experiencenear discussion of the application of these views to the construction (emergence) of experience and the creation of new meaning in therapy. Finally, we will analyze a segment of a transcript from a therapy session in an attempt to ground the more abstract theoretical concepts in the moment by moment construction of meaning in a therapy session.

\section{THEORY OF CONSTRUCTIVE OPERATORS}

In our view, consciousness is a major arbiter of meaning by way of selecting the source of information to which to attend and the interpretation to be favored. Consciousness involves components of will and choice. These are partly conscious processes by means of which people bring their mental attention under the influence of internal, executive-like processes (Pascual-Leone, 1990a). But consciousness is influenced by a number of additional factors. Among the most important are immediate emotional experience, the salience of external stimuli, the views and attitudes of others toward self, and the past responses of the self in similar situations. Consciousness is overdetermined by all of these factors and more (Pascual-Leone, 1984, 1987, 1990a). It is, however, the arena for a final synthesis of different sources of sensory, kinaesthetic, emotional, conative, and conceptual information about the self and the world.

Driven by affect, people are active constructors of meaning. Affect is neuropsychologically independent of cognition, and informs the individual, through visceral sensations and action tendencies, of its unconscious evaluative responses with regard to body, self, and world. Emotion gives people feedback about what is important and meaningful, what is good or bad for them (Frijda, 1986; Izard, 1977). It, thus, is a meaning system that informs people of the significance of events to their well-being. Personal meaning results from the self-organization and self-explication of one's own emotional experience. People are constantly representing themselves to themselves and to others in images, actions, and narratives, and they continuously construct views of themselves in consciousness. 
The most important experience-generating, subjective processor is the scheme (schemes are semantic-pragmatic structures of various levels of complexity), formed by different kinds of learning, both associative and conceptual (Pascual-Leone \& Johnson, 1991). The generation of much emotional experience is driven initially by automatic processes that produce primary responses following simple perceptual appraisals (Greenberg \& Korman, 1993; Scherer, 1984). Automatic processes are followed immediately by more complex activity in which sensory, memorial, and ideational information is integrated, yielding a felt sense of oneself and the world. This higher level synthesis of a variety of levels of processing has been referred to as an emotion scheme, and has been identified as a principal target of therapeutic change (Greenberg, Rice, \& Elliott, 1993; Greenberg \& Paivio, 1997).

However, as Pascual-Leone $(1984,1987)$ has pointed out, schemes alone are insufficient for explaining how novelty arises. It is only by differentially allocating attention to certain elements, and by interrupting the application of misleading schemes (disattending to misleading cues in the situation), that people can create truly-novel performances and configurations of experience. Novel dynamic syntheses thus occur, produced by the interaction of a variety of subjective special-purpose processors (schemes) and a variety of metasubjective, innate, general purpose processors (hardware operators) (Pascual-Leone, 1984, 1987, 1990a, 1995; Pascual-Leone \& Baillargeon, 1994; PascualLeone \& Goodman, 1979; Pascual-Leone \& Irwin, 1994, 1998). The hardwired, higher level, metasubjective processors that influence which schemes will dominate in a synthesis include affect, mental effort, and a field closure factor.

The affective $(A)$ operator begins as an inwired purely affective, neurophysiologically-based response system. With development and experience, this becomes a complex emotion-schematic processor that has integrated affective responses with cognitive experiences to produce complex emotional experiences (Greenberg \& Safran, 1987; Leventhal, 1984; Pascual-Leone, 1991). The mental effort mechanism (PascualLeone, 1987; Pascual-Leone \& Baillargeon, 1994) is constituted by both a central attentional energy resource (or $M-$ for mental operator) and a central attentional active inhibition (or $I$ - for interruption operator) - the two attentional resources (operators) are mobilized and allocated by the subject's executive schemes ( $E$ operator, see below). The mentalattentional $(M)$ operator increases its capacity with development, and acts to boost the activation weight of task-relevant schemes in the dynamic syntheses that produce performance. The attentional general inhibition mechanism ( $I$ operator) can interrupt the application of misleading schemes when allocated to them. Finally, the field closure 
operator $(F)$, that is, the Gestalt simplicity principle, induces the completion of experience as a totality (Greenberg \& Pascual-Leone, 1995; PascualLeone, 1984, 1987, 1996; Pascual-Leone \& Morra, 1991). In addition to the above hard-wired operators, executive schemes are constantly being formed to act as situated guides to processing. These executive schemes, when considered together as a repertoire or set, constitute an E operator (Pascual-Leone, 1987; Pascual-Leone \& Baillargeon, 1994). These schemes mobilize and suitably allocate the $M$ and $I$ operators, so as to induce experience/performance that conforms to current affective goals.

\section{Levels of Processing}

The sequence of dialectical moments that occurs in the generative construction of here and now performance or experience (Pascual-Leone, 1984, 1990a, 1990b) is shown in Figure 1. Five basic levels of processing are involved: automatic action processing, affective processing, executive choice processing, conscious effortful processing, and conscious experience/performance processing. In the figure, by tracking the forward flow of the arrows, we can see that input activates automatic processing (Level 1), and this processing can directly produce perceptual/motor experience. Thus, by an unconscious process of selection (dynamic synthesis), a certain configuration is chosen after the input which results in the first automatic moment of construction at the action processing level. Then this sensory and motor (bodily or external) content will cue the affective level of processing (Level 2), and again a silent choice among alternatives occurs (by dynamic synthesis) that results in the output of an affective goal or goals. The affective goal then activates exploratory preexecutives and actual executives (Level 3). Executive processing activates procedures and plans for action as well as controls, which mediate more elaborate performances/experiences. This level of processing results in the more conscious choice of task executives for governing performance/experience on the current task, as well as corresponding control executives for controlling the hardware operators that are needed to mediate in producing performance/experience. This choice results in conscious effortful processing and effortful choice (Level 4), which produces final experience/ performance (Level 5).

There are two things to note. First, the executives here are informational processes, each representing components of plans, rather than containing exhaustive, fully formed, plans. Executive schemes then jointly determine a course of action, by overdetermination. All the various 


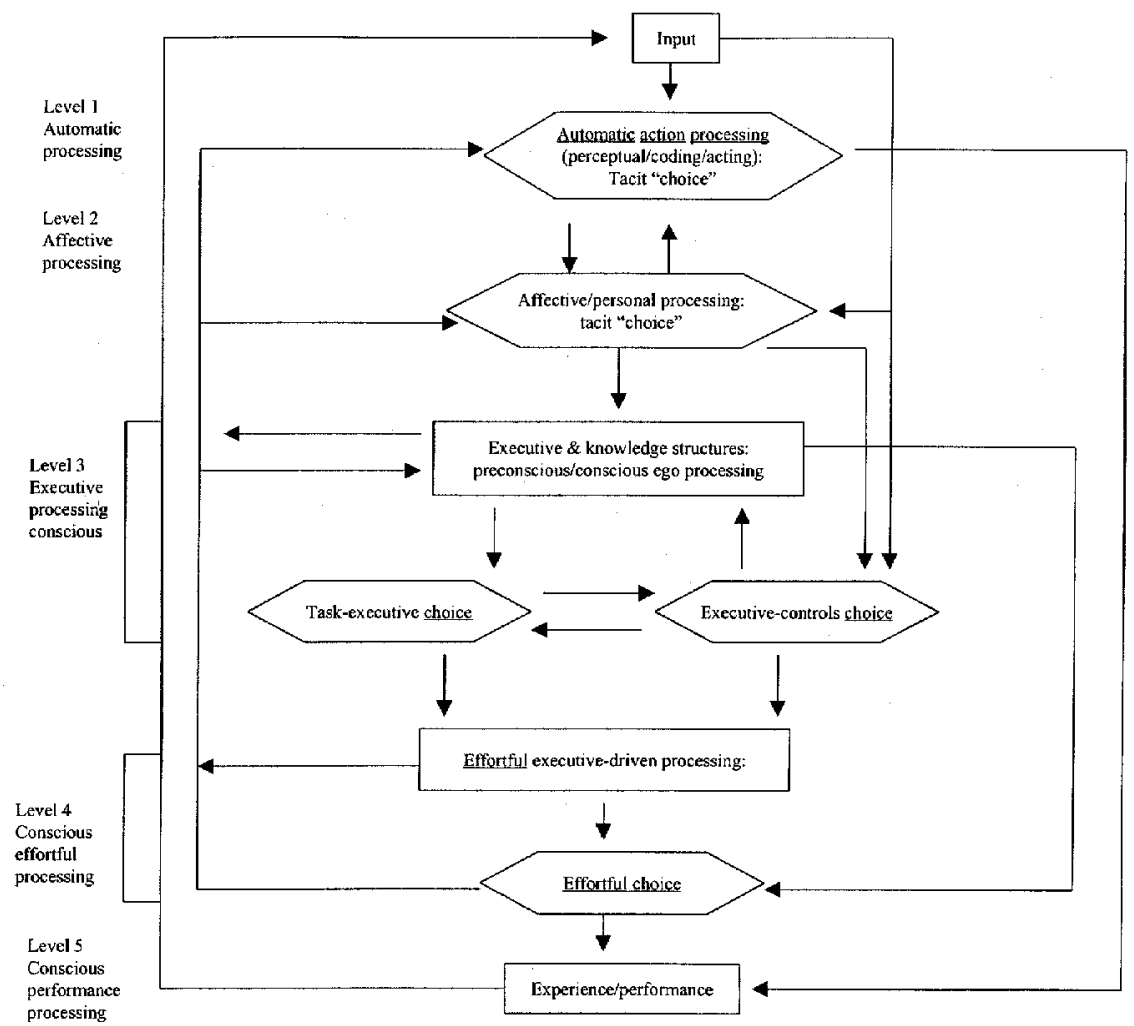

FIGURE 1 Control flow among levels of processing (dialectical "moment") during generative construction of here-and-now performances. (Note: Mediation increases as one moves down the diagram. Diamond shaped boxes represent where/when a dynamic choice occurs. Experience/Performance is generally the result of many reverberations around the system. This figure is modified from Pascual-Leone, 1990, Figure 12.1, with permission.)

schemes at other levels boost certain executives, and the executives that are most strongly boosted combine to form a more or less coherent or complete task plan, which is implemented in the levels of processing that follow. This account, thus does not refer to the classic view of an executive as a homonculus that, in advance, specifies what to do, but rather to the idea of many executive schemes, (some of them dynamically synthesized in the situation) that together guide performance/ experience. Secondly, in Figure 1, there are a large number of alternative sequences that lead to different types and levels of processing and often different outcomes. Thus any experience/performance may be 
produced by different levels of processing. Problems in personal meaning construction may arise through such processes, as conflicts between levels of processing, via the generation of purely conceptual, inauthentic experiences / performances that are not deeply processed, or by the activation and synthesis of maladaptive schemes (Greenberg \& Paivio, 1997).

Once the self-organizing, tacit processes of Levels 1 to 3 produce a performance, or an experienced sense of self, a sense that is experienced by us as simply happening to us (this is a felt form of awareness, our sense of self not yet completely conscious), consciousness (Levels 4 and 5) often selects aspects to amplify or symbolize. For further discussion of this idea of a progressively emergent self that is tied to both affect and consciousness, see Damasio, 2000; Pascual-Leone, 2000; Pascual-Leone \& Irwin, 1998; and Whelton \& Greenberg, 2000. At any moment, there are always more processes occurring in the internal field than can be simultaneously represented/symbolized into complete consciousness. Generally, only aspects that are consistent with a preferred view of self are so amplified and symbolized.

The individual is, thus, continually constructing a particular view of self by constantly selecting some schemes/elements of experience (internal or external) and ignoring other aspects. Meaning emerging from these selected processes is neither simply imposed by language and consciousness, nor is it wholly contained in automatic, raw experience. Rather, it results from repeated dialectical syntheses of the many different levels of information processing discussed above. Conscious construction of meaning is continually guided by an implicit emotionally-based felt sense of meaning, and culminates, perhaps, in the capturing of this felt sense in language. The felt sense itself results from an automatic dynamic synthesis of affective and cognitive processes that contributes to the individual's internal complexity. We define internal complexity as the person's experience of the ongoing dialectical syntheses of meaning and processes of activation, of the emotional and cognitive schemes (Levels 1 to 3 ) activated in the internal subjective field. When attended to, and elaborated, this internal complexity is symbolized in reflective awareness, thus creating distinctions of experience that can then be further elaborated by conceptual processing (Levels 4 and 5) to generate vital explanations or new meanings.

\section{Schematic Processing in the Construction of Experience}

The subject's modes of schematic processing and the role of emotion and cognitive schemes in the generation of experience are depicted in 
Figure 2. The levels of processing depicted in Figure 1 are integrated into this diagram by means of labels, to show the functional processes in which different schemes are involved. In this schematic processing diagram, we see that input is processed through sensorial and automatized perceptual/image/action schemes (Level 1), to activate basic affective/emotion schemes (Level 2), and independently, cognitive schemes (Level 3), which may also be activated via affect. When mental attention is mobilized (i.e., $E, M$ and $I$ operate), conscious emotional experience and thought (Level 5) are produced. Activation of schemes is influenced by the attentional resources (Level 4) allocated to them, which enable them to be symbolized in consciousness resulting in feelings and thoughts. Feelings and thoughts then interact, mutually influencing each other, to produce conscious emotional/cognitive mentations, the stuff of internal dialogue, and the source of a final response. Finally, the output is brought about by all preconscious and conscious processes in dynamic interaction with each other, mediated by perceptual motor schemes that produce the final concrete experience and performance. Notice that output feeds back into the situation becoming new input, that again influences the activation of emotional schemes.

As we have said it is important to recognize that at least two distinct modes of meaning creation (i.e., the affective and the cognitive) are always operating, respectively guided by the affect/emotion schematic (AEmS) mode and the purely cognitive schematic mode (CS). The former is a deeper expression of the person and is the level of processing responsible for immediate emotional experience. This emotional schematic processing leads to a conscious emotional experience (CONS. Em), and often influences conscious thought and conceptual processing (CONS.T), as is apparent in mood-dependent cognition. Thoughts, however, are also influenced directly by purely cognitive schemes that have been independently activated by the input. Functional relations among these processing modes are symbolized in Figure 2.

All these processes work in the following manner in the creation of personal meanings. At any moment, a variety of affectively based schemes, formed from a person's inwired emotion response system and prior emotional experience, and cued by the situation, are activated in the internal field. They orient the person to the environment and activate relevant executives which in turn mobilize and allocate attentional resources to other relevant schemes. Thus, some aspects of the situation, for example, may evoke fight/flight, approach/withdraw, cry out/close down or tend/befriend tendencies. These tendencies in turn begin to activate either a scanning of the environment for threat, or the joyful opening of oneself for contact, and they generate mood congruent implicit beliefs such as "the world is a dangerous place" 


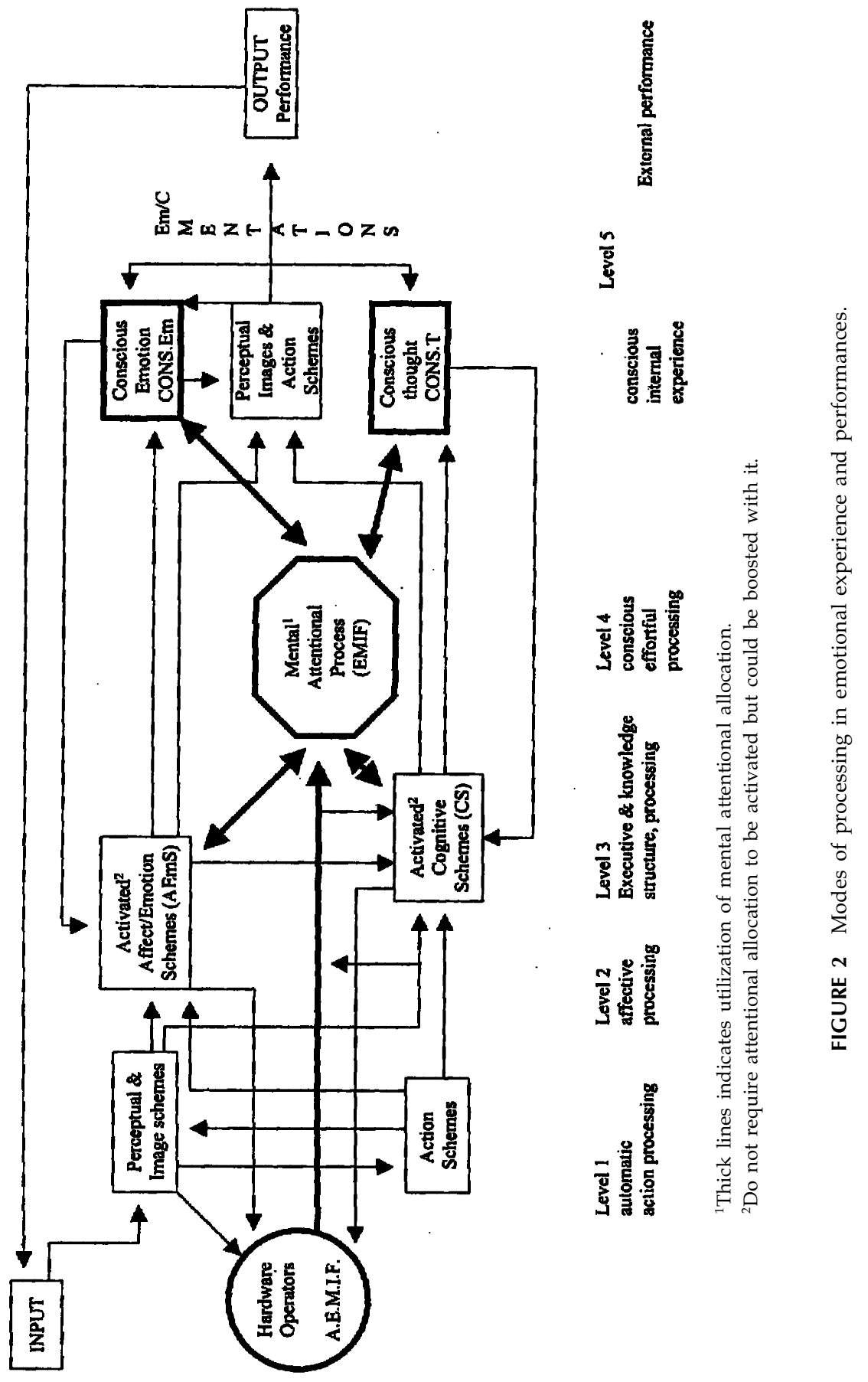


or "others are trust-worthy." The activation weights of some of the relevant activated schemes are in addition strengthened by being boosted further, both by deliberate attentional allocation and by affectively aroused compatible goals, such as desires for status or intimacy, aroused by other aspects of the situation. In addition, some schemes are inhibited (interrupted) by the general-purpose interruption operator. Thus tendencies to run away or to approach someone may deliberately be inhibited, due either to awareness of one's own tendencies as inappropriate to the situation, or anxiety (self protective/defensive processes). At the same time as all these other operators are influencing the schemes' weightings, the currently activated schemes that can best produce the simplest structural closure of experience will also be boosted by the field factor (F-operator). Thus, the person may end up assiduously avoiding someone at a cocktail party, or seeking him out. The set of activated schemes is therefore synthesized into a unified performance / experience via a process of summation of the schemes' activation weights followed by application of the dominantly activated schemes, which by overdetermination, synthetically generate the final performance or experience. The result maximizes internal consistency and external adaptation, while minimizing internal complexity (PascualLeone, 1987; Pascual-Leone, 1991) - that is, what Piaget would have called (organismic) equilibration.

Note that experience is created by a dialectical interaction between metasubjective hardware operators and executives, and subjective software schemes - it is not created simply by schemes alone (PascualLeone, 1984, 1987, 1995, 1996, 1997; Pascual-Leone \& Johnson, 1999). A narrative is then created by a second, higher level, dialectical interaction between experience and symbols. It is important to note also that in this process it is the hardwired organismic operators $M, I$ and $F$ that are responsible (due to the overdetermination of experience/ performance within the organism) for the tacit dynamic syntheses, or choices, which mediate performance and experience (Greenberg \& PascualLeone, 1995; Pascual-Leone, 1987, 1995, 1996; Pascual-Leone \& Johnson, 1991; Pascual-Leone \& Morra, 1991). This mediation makes the organism higly active and self organizing.

\section{PSYCHOTHERAPY AND EMOTIONAL MEANING}

The above model suggests that processes generating emotional experience occur independently of and, often prior to, conscious cognitive operations. Therefore, working only at the cognitive level (Levels 3, 4 \& $5)$ to effect affective/emotional change is likely to prove ineffectual. 
Instead, interventions need to target the affect/emotion schematic processes (Level 2), that automatically generate emotional reactions and the felt sense of oneself in the world. Change in these schemes is produced by accessing them so they are up and running, and by making new information and experience available to them, so that they accommodate (learn) to construct new adapted schemes (Greenberg \& Safran, 1987, 1989; Greenberg et al., 1993; Greenberg \& Paivio, 1997). Thus, therapy has to facilitate clients' access to their affects/emotions (and inner experiencing) during the session. A variety of techniques can be used, including asking the clients to evoke events vividly and concretely to focus on a bodily felt sense, or to imagine a significant other to evoke an emotional response.

Emotions are evoked (Level 2) in therapy so that they can be represented symbolically and reflected on (Levels 4 \& 5). Clients' attention to their emotions in therapy, and their ability to represent and reflect on them, leads to accessing previously unavailable internal motivation that produces novel responses and can lead to enduring change. Clients use reevoked emotional experiences to differentiate meanings implicit in their reactions, and to discern the impact on them of events, internal processes, and significant others. Negative emotions, in particular, often alert people to problematic aspects of experience that require attention. Affects and emotions often signal that one's needs /goals have not been attained; and this sets problems for reason to solve. We thus see that much cognition is in the service of affective goals, and that emotion informs reasoned action (Greenberg \& Paivio, 1997; Pascual-Leone, 1991). Emotions might, for example, tell one that something is wrong in the domain of interpersonal relations, such as an interpersonal bond that has been ruptured or endangered. Thinking then sets to work to create a solution to this problem.

\section{THE INTERNAL DIALECTICS OF MEANING MAKING}

\section{The Three Vital Moments}

Construction of conscious personal meaning in therapy involves three vital moments (Watson \& Greenberg, 1996). First, the synthesis of a feeling or felt sense (Levels 1-3); second, a moment of attending to this bodily felt sense, consciously symbolizing it to form a subjective reality (Level 4); and third, a moment of reflection in which explanations of the symbolized experience are generated to produce a coherent narrative and/or conceptualized self identity (Level 5). It is the combination of these three processes of synthesizing feeling, attending 
and symbolizing, and reflecting explaining, that leads to the stable construction of new views of self and reality in therapy and in life.

\section{Synthesis of Bodily Feelings}

As pointed out, a bodily felt sense or a feeling arises by means of the internal dynamic synthesis of an set of emotionally based schemes with other cognitive schemes activated in a particular situation. Imagine, for example, telling a friend the story of an occurrence the previous evening, one of standing in line for a movie, and then turning around and suddenly seeing someone whom you either wished desperately to avoid or whom you were amorously longing to meet. Depending on which occurred, you might be able to speak at length from two entirely different senses of internal complexity generated in the moment. You could talk about how you felt in, and about, this moment, drawing on all kinds of different images and explicating complex felt meanings and their implications. All these tacit meanings occurred in the field of internal complexity but were not necessarily processed consciously prior to opening your mouth and greeting the other person. What is uttered in the moment is itself a complexly overdetermined performance from internal complexity. It could be either coolly dismissing or charmingly disarming, if one is sufficiently socially adroit, or could be clumsily awkward, if one is overwhelmed by the emotions in his /her own internal complexity. Thus, beyond the specific performance generated, at the periphery of awareness, in the internal field of activation, lies a host of bodily felt meanings that, with attentional allocation, can be brought to awareness and articulated (James, 1980; Perls, Hefferline, \& Goodman, 1951).

The bodily felt referent (Gendlin, 1962), to which one can attend, and from which one speaks in order to unpack the host of situated meanings, is filled with the implications of the components by which it has been constituted. In the case of seeing the desired person, the situation is filled with one's feelings, wishes, hopes, dreams, and evaluations of self worth, including evaluations of one's looks, body, intelligence, and social abilities as well as many other idiosyncratic meanings. In the case of seeing the dreaded person, one's fears and resentments, one's evaluations of one's self worth, competence, and rights, one's abilities to deal with this aversive situation, as well as other idiosyncratic elements fill the situation.

It is important to note that this bodily felt sense is not only multidetermined by many modalities and modes of processing, such as auditory, visual, kinaesthetic, emotional, and semantic, but is also 
overdetermined. That is, the result is produced by as many determinant causes as there are compatible processes that might jointly inform the performance. Experience is produced by more than one set of causes, even if a partial set of all the determinants found therein often would suffice to produce the same result. An experience thus means both this and this, even though the two determinants may differ, and either could have sufficed to produce the result. Explanation of why one feels or does something is thus not a simple rational or linearly causal process. We experience things for many reasons, all of which converge to overdetermine the final state.

\section{Symbolizing and Explaining}

Within a dialectical perspective, we view people not only as living their lives - the first stream of consciousness (Levels 1 to 3 ) - but also as being compelled to evaluate and make meaning of their lives - the second stream (Levels $4 \& 5$ ). In order to better understand themselves, people continually symbolize and explain themselves to themselves, forming an ongoing narrative of who they are as they become. In this manner, their stable identity emerges. Self-explanations, however, can be more or less veridical. A dramatic illustration of this is offered by Gazzaniga (1985) who showed in split brain patients' that the left hemisphere makes up rational, but false, reasons to explain verbally those actions driven, unaware, by the right hemisphere.

\section{Symbolizing}

The symbolic and reflective (often sequential and propositional) level of conceptual processing differs from the experiential (holistic) processing of patterns of emotional relevance described above (Epstein, 1993; Greenberg et al., 1993). The bodily felt sense (Levels 1 to 3), however, acts as a constraint on the possible conscious symbols and narratives (Levels $4 \& 5$ ) that can satisfy it, eliminating many possible symbolic personal meanings that are grounded in experience. A crucial part of a personal meaning-making process is the production of linguistic distinctions to express this implicit bodily felt sense of meaning. For instance, one might symbolize a given internal sense as feeling tired or disappointed or depressed. All these synthesized meanings, reflect experiential constraints in a way that saying that one feels "happy" or "afraid" would not. The symbols "tired" or "disappointed" or "depressed" are each adequate, but each captures different aspects of the total experience. Conscious experience is thus not simply in us, 
fully formed, rather it develops further as we put words to our feelings. Articulation, most often in language, is crucial in the creation of new conscious meaning.

Human nature, however, does have its own order, based on inborn emotional/motivational tendencies; it does not always follow the order imposed upon it by language and culture. No socially derived symbol can accurately reflect a given experience. An inaccurate, externally imposed, symbol cannot create new lived experience and it might ultimately cause greater disturbance and confusion if mistakenly accepted. People must be guided by their own emotionally based internal complexity (Levels 1 to 3 ) arising from interaction with the particularities of the situation. This internal complexity induces a bodily felt sense of meaning (Gendlin, 1962, 1964, 1968), which, when attended to and symbolized, helps conscious experience to unfold.

\section{Reflection}

Once clients have expressed and clearly articulated their feelings in symbols, they are in a position to reflect on (and evaluate) their experiences and actions in the light of current goals, needs, and values. These activities produce explanations and cognitive reorganization. Pennebaker (1990) has shown that talking and writing about emotionally traumatic experience immediately causes a drop in skin conductance and blood pressure, and improves long term health and immune function. Particularly striking are results of subjects writing for $15 \mathrm{~min}$ utes a day, for four days, about the most traumatic experience of their lives. They consistently evidenced significant drops in the number of visits to physicians, and showed enhanced immune functioning. Analyzing these subjects' essays, Pennebaker (Pennebaker \& Traue, 1993) observed that the writing appears to force people to stand back and reorganize their thoughts and feelings. Subjects commented that the process of writing made them think things out and look at themselves from outside; it helped them sort out their thoughts. This report suggests that reflective elaboration and meaning creation are important therapeutic consequences of emotional expression. But to achieve them, psychotherapeutic interventions need to go beyond techniques that simply encourage emotional expression or self disclosure; they also need to focus clients on the creation of new meaning from the aroused emotional material.

In deciding who they are, people are strongly influenced by the sources they use in generating narrative explanations and self-evaluations that constitute their identities. Top-down, conscious explaining is highly dependent on both cultural learning and what is attended to. 
In healthy meaning making, people's self reflections are based predominantly on their bodily felt sense, generated bottom-up by emotional and sensorimotor processing. Explaining, however, can also be based on more socially-acquired cognitive schemes that were obtained from others or inferred from past experience. Although often useful values, these may also be sources of psychological difficulty. Those explanations, that favor image maintenance over experience and interfere with perception, have been viewed as guided by "learned conditions of worth" (Rogers, 1951) or "introjects" (Perls et al., 1951), or "faulty assumptions" (Beck, 1976). Whenever identity is overly controlled by these exogenous determinants, people are not grounded in their own primary experience, and dysfunction may result. However, without higher level reflections and evaluations of their primary emotions and desires, people do not have an identity or a sense of agency.

\section{Development of the Self}

Infants' emotional systems are involved in rapid evaluation of what is good or bad for them. Infants, right from birth, experience feelings, and as soon as they can construct schemes of sufficient complexity (Pascual-Leone, 1991, 2000; Pascual-Leone \& Irwin, 1994; Pascual-Leone \& Johnson, 1999) they use these feelings to construct a conscious personal sense of self. A major determinant of this self construction is their intersubjective experience associated with their own automatic emotional reactions. An individual's sense of self is primordially organized around emotional schemes formed in primary-attachment relationships. Affect regulation develops with maturation but also with the way caretakers react to the child's emotions; these experiences determine the affectively based sense of self. The views of others about one's emotional experience are synthesized with one's own internal experience to form emotion schematic records of self and circumstances. These emotional schemes become the core structures of the person and guide further growth. How one symbolizes one's internal states evolves in an intersubjective manner, and the "I" comes to see itself as a particular "me," mediated through others' views of, and responses to, the self (Guidano, 1987, 1995; Stern, 1985).

To summarize, language and bodily experience, derived respectively from culture and biology, play a critical role in constituting people's identities. Immediate experience influences, but is also influenced by, how identity is formulated. This circumstance sets language and experience in a circular causal relationship. Identity results from dynamic syntheses of direct experience with learned views of self. But people 
do not only synthesize self representations. They also consciously examine them and select syntonic views of self and alternatives for action.

Meaning creation in therapy relies on three critical moments: The activation and synthesis of affect/emotion schemes (AEmS Level 2); the symbolization in awareness of bodily felt experience (EMIF Level 4 ), and the reflection on explanation of symbolized material (CONS.Em \& CONS.T Level 5). Dialectical syntheses of different modes of processing that occur at different levels serve to produce new personal meaning. The two most critical levels involve the synthesis of tacit or preconscious schemes (Levels 2,3) to form a suitable sense of internal complexity. This experientially/existentially grounded internal complexity, is further synthesized with a more conscious process (Levels $4,5)$, resulting in experience (Levels 1, 2,3) and explanation (Levels 4, 5) being integrated to form emotionally motivated and reasoned, action and reflection. This is the synthesis that gives birth to a genuine narrated view of self.

\section{Creation of Meaning in Therapy}

A fundamental task of therapy is the symbolizing of subjective emotional experience, to understand it and unfold its implicit action tendencies (Greenberg, Rice, \& Elliott, 1993). Change in psychotherapy results from symbolization in awareness of truly novel dynamic syntheses occurring in an internal field of activation. This often involves a process of activating and restructuring affect/emotion schemes (Greenberg \& Paivio, 1997). Emergence of new meaning is facilitated by vivid evocation in therapy of emotionally laden experience, which brings emotions into contact with reflective processes. Dialectical syntheses of emotion and reflection are important in therapeutic change. Promoting clients' access to their emotions in therapy serves a number of important functions. First, it provides the therapist and the client with information about the meaning of events, and also about the client's needs, desires, beliefs and values. Second, access to emotions serves to organize experience, because emotions help to set priorities about what requires immediate attention and what actions shall be performed. Third, access to emotions tells clients when there is something wrong, and this awareness of existential/experiential problems motivates problem solving. Finally, expression of unexpressed or stifled emotional responses helps access dysfunctional beliefs and can mobilize unexpressed needs and goals that address the future (Greenberg \& Korman, 1993; Greenberg \& Paivio, in press).

A brief segment of the beginning of a transcript from an actual 
session of psychotherapy is provided here and subjected to a preliminary task analysis (Greenberg, 1991; Pascual-Leone, 1989; Pascual-Leone \& Johnson, 1991, 1999, 2000; Stewart \& Pascual-Leone, 1992) to identify types of schemes and processes operating at each moment. In this analysis, the modes of processing used by the client are speculatively inferred from the content and manner of her utterances, from how emotionally expressive, and conceptually explicit, elaborative, or novel in content they are. This analysis is summarized in brackets indicating the modes and levels of processing of Figure 2, by their symbols. Arrows and double arrows are used to indicate the sequence of change in modes of processing. In addition, the emergent and transformed novel content in the statement itself is underlined.

The client's second utterance C2 below is fully described to clarify the meaning of the notations. The following symbols from Figure 2 are used in the task analysis. AEmS = Emotion scheme, E = Executive, $\mathrm{M}=$ Mental attention, $\mathrm{I}=$ Interrupt, $\mathrm{CS}=$ Cognitive Scheme, CONS.Em $=$ Conscious Emotion, CONS.T $=$ Conscious thought, $\mathrm{Em} / \mathrm{C}=$ conscious mentation/reflection, L2 = Affective processing, L3 = Executive processing, L4 = Conscious effortful processing, L5 = conscious experience/performance.

\section{TRANSCRIPT}

In this excerpt a 35-year-old mother of two, with a major depression, begins her ninth session in a distressed state, feeling discouraged and hopeless. In this brief segment the therapist $(\mathrm{T})$ works with the client (C) to help her articulate the sense of loneliness that relates to her struggles both in her marriage and her family of origin. We see how she begins to make sense of her experience by attending to an aroused feeling, symbolizing it as an inner emptiness, and reflecting on how it has led her to give in order to receive.

T: What's happening now?

C1: Just like I mentioned, um, uneasiness, or I guess maybe anxiety comes up because, um - there's a bit of, it's frightening or um (Conscious emotion leads to conscious thought: CONS.Em, $\rightarrow$ CONS.T, L5)

T: Can you kind of go to that place right now? (C: um-no) Is it hard to go there? (Attend to bodily felt sense)

C2: Yeah it's like, well it's not hard it's, it's the loneliness is there and I feel like what I'm looking for is, comfort. (T: Uh huh) Um being told that I matter. (T: Yeah, that's what you'd like.) Reassurance-I guess (Activate emotion scheme and symbolize in consciousness: AEmS, L2 $\rightarrow$ E, M, I, L4 $\rightarrow$ CS, L3 \& CONS.Em, L5 $\rightarrow$ CONS.T, L5). 
At the beginning of the utterance, the client's hesitation ("it's, it's . .), her directness and exclusive reference to emotion suggests that she is accessing an affective/emotion scheme, perhaps via CONS.Em (i.e., conscious emotion). The mode of processing, possibly leads to the affect-driven mobilization of mental attention (EM I-E-Executives, $M$-capacity, and I-Interruption or inhibition). This mental attention energizes and activates Cognitive Schemes (CS) and Conscious Emotion (CONS.Em), allowing her to elaborate analogically the feeling ("I feel like what I'm looking for is comfort. ...") Finally, a Conscious Thought (CONS.T) is reached permitting a more detached socially-based explication ("being told that I matter . . . reassurance I guess").

T: Yeah, somebody to say "Yeah, it's okay, Cindy." (Evocative intensification)

C3: Yeah (crying). I'm just, I guess to just hear it from somebody else, and (T: Uh huh) and, um, I mean, just repeating to myself. (Conscious cognitive elaboration-explaining: CONS.T, L5 \& CONS.Em, L5)

T: Uh huh. It's like hard to keep doing it all on your own. (exploration)

C4: Yeah yeah, it is, that's right, it's like always there. (Attend to bodily felt experience: CONS.Em, L5 $\rightarrow$ AEmS, L2)

T: Sort of a constant feeling of wanting something. (Attend \& explore)

C5: Yeah, yeah. That's always there. (T: Uh huh)-I guess I just need to reassure myself that, you know, it's going to be okay. (T: $\mathrm{Mm} \mathrm{mm}, \mathrm{hm} \mathrm{hm}$ ) You know that-you do have friends that care and, um, family and, yeah, I guess just need reassurance. (Conscious cognition reflexive examination \& explaining: CONS.T, L5 $\rightarrow$ CONS.Em, L5 $\rightarrow$ E, M, I, L4 $\rightarrow$ AEmS, L2 $\rightarrow$ CONS.Em, L5 \& CONS.T, L5)

T: But just something, there's, there's something you want out theresome kind of reassurance. (Explore and encourage symbolization)

C6: $\mathrm{Mm} \mathrm{hm}$. Yeah. I guess I'm the type of person that needs to hear that, or again because I've always been, always been giving and, um, not I guess, I didn't get it back to me. Um, that make, makes me feel maybe like, um, you know, I've been ripped off or . . (T: $\mathrm{Mm} \mathrm{hm}$ ) (reflexive examination activates new emotion scheme which is symbolized: CONS.T, L5 $\rightarrow$ E, M, I, L4 $\rightarrow$ CONS.Em, L5 \& AEmS, L2 $\rightarrow$ CONS.Em, L5 $\rightarrow$ CONS.T, L5)

T: So there's a feeling of being cheated too. (C: Cheated, yeah.) What's that like? "I've given and given and given and what have I got for this?" kind of thing? (Attend to and explore emotion scheme) 
C7: Right, yeah, "Why isn't it coming back to me?" or (T: Mm hm) it's prolonging, like it's been a very long time. (conscious reflexive examination: CONS.Em, L5 $\rightarrow$ AEmS, L2 $\rightarrow E, M, I$, L $\rightarrow$ CONS.T, L5)

T: So you're getting a bit fed up with it, like, "It's been a long time since I've been giving and putting out." (Intensify Attentional Allocation)

C8: Yeah, "When is it going to be my turn too?" Not that I want to receive, as in gifts and stuff, but just (T: Yeah) to mean that I count that I'm there for a reason (T: Yeah) to be told that (sniff). . . . (Conscious cognition, reflexive examination: CONS.T, L5 $\leftrightarrow$ CONS.Em, L5)

T: Yeah. Like you've sort of become more aware now of what you need, right?

C9: Yeah, um and maybe this is why, um, I give, give because I guess the emptiness - it makes me feel good like when I do that, but then inside, um, well it seems like a hole. (conscious cognitive reflexive examination then attends to emotion scheme: Em $/ C \rightarrow E, M, I, \mathrm{~L} 4 \rightarrow$ AEmS, L2 $\rightarrow$ CONS.Em, L5 $\leftrightarrow$ CONS.T, L5)

We see that in this process the client, with the therapist's help, makes sense of her emotional experience. She attends to her felt loneliness and need for reassurance and identifies an inner emptiness. Reflecting on this, she constructs a feeling of being cheated, of needing confirmation, and forms an explanation of her behavior. She sees herself as giving as a way of filling the emptiness. She engaged in a process of attending, symbolizing, and reflecting in creating this new meaning. This involved moving between levels of processing and tacitly operating on a variety of schemes to synthesize these into her final conscious experience.

\section{CONCLUSION}

Affects and emotion serve as organizing forces in human functioning and play a key role in the development of personal meaning. Affect / emotion, in conjunction with the allocation of mental attentional energy, guides conscious cognition and makes individuals active determiners of their conduct rather than passive reactors to stimuli. One of the primary goals of a constructivist emotion-focused therapy is the evocation of various emotional states in a variety of different in-therapy contexts. This is done to help clients to become aware of the adaptive action tendencies emanating from their own emotional states, to restructure 
their emotional experience, and to create new meaning by understanding the impact of events on them, and the significance to them of events and of people. They can then analyze and reflect on their experience to solve the vital problems of living and feeling.

A dialectical constructivist view offers two major avenues of change. One is in helping people change the way in which they order their experience in language, and, via this conceptualization, change their way of living. This involves producing change in the conceptualization or explanation of experience. Generating symbols to explain experience, and engaging in reflection, promotes the construction of new narratives. The second avenue of change is to promote novelty in the generation of emotional experience itself. Here by altering tacit dynamic syntheses through attentional allocation, interruption, and activation of different emotion schemes, new experience is synthesized in the field of internal complexity. This creates the possibility of producing change in emotional experience itself. This is then symbolized and used to change the narrative. This later avenue introduces the possibility of a new change process. Changing emotion with emotion (Greenberg \& Bolger, 2000). Here transformation occurs by accessing new emotional possibilities that were not previously accessible in order to change more dominant maladaptive emotional responses. Thus, anger may be accessed to empower and transform fear or shame. Sadness or compassion may be accessed to soften anger. Here affect syntheses or blends, change experience, and this changed experience is then symbolized in awareness.

\section{REFERENCES}

Beck, A. T. (1976). Cognitive therapy and the emotional disorders. New York: International Universities Press.

Bohart, A. (1993). Experiencing: A common factor. Journal of Psychotherapy Integration, 10, 14-37.

Damasio, A. (2000). The feeling of what happens. San Diego: Harvest, Harcourt Inc.

Epstein, S. (1993). Integration of the cognitive and the psychodynamic unconscious. American Psychologist, 49(8), 709-724.

Frijda, N. H. (1986). The emotions. Cambridge: Cambridge University Press.

Gazzaniga, M. S. (1985). The social brain: Discovering the networks of the mind. New York: Basic Books.

Gendlin, E. T. (1962). Experiencing and the creation of meaning: A philosophical and psychological approach to the subjective. New York: Free Press of Glencoe.

Gendlin, E. T. (1964). A theory of personality change. In P. Worchel \& D. Byrne (Eds.), Personality change. New York: John Wiley.

Gendlin, E. T. (1968). The experiential response. In E. Hammer (Ed.), Use of interpretation in therapy (pp. 208-227). New York: Grune \& Stratton. 
Greenberg, L. (1991). Research in the process of change. Psychotherapy Research, 1, 14-24. Greenberg, L., \& Bolger, L. (2001). An emotion focussed approach to the over-regulation of emotion and emotional pain. In-Session, 57, 197-212.

Greenberg, L. \& Korman, L. (1993). Integrating Emotion in Psychotherapy Integration. Journal of Psychotherapy Integration,

Greenberg, L., \& Paivio, S. (1997). Working with the emotions. New York: Guilford Press.

Greenberg, L., \& Pascual-Leone, J. (1995). A dialectical constructivist Aapproach to experiential change. In R. Neimeyer \& M. Mahoney (Eds.), Constructivism in Psychotherapy. Washington, DC. American Psychological Association.

Greenberg, L. S., \& Safran, J. D. (1987). Emotion in psychotherapy: Affect, cognition, and the process of change. New York: Guilford Press.

Greenberg, L. S., \& Safran, J. D. (1989). Emotion in psychotherapy. American Psychologist, 44, 19-29.

Greenberg, L. S., Rice, L. N., \& Elliott, R. (1993). Facilitating emotional change: The moment by moment process. New York: Guilford Press.

Greenberg, L., \& van Balen, (1998). Theory of experience cntered therapy. In L. Greenberg, J. Watson, \& G. Lietaer (Eds.), Handbook of experiential psychotherapy: Foundations and differential treatment. New York: Guilford Press.

Guidano, V. F. (1987). The complexity of the self. New York: Guilford Press.

Guidano, V. (1991). The self in process. New York: Guilford Press.

Guidano, V. (1995). The constructivist psychotherapy: A theoretical framework. In R. Neimeyer \& M. Mahoney (Eds.), Constructivism in psychotherapy. Washington, DC: American Psychological Association.

Hermans, H. J. M., Kempen, H. J. G., \& van Loon, R. J. P. (1992). The dialogical self: Beyond individualism and rationalism. American Psychologist, 47, 23-33.

Izard, C. (1977). Human Emotions. New York: Plenum.

James, W. (1980). The principles of psychology. New York: Holt. (Reprinted, New York: Dorer, 1950).

Johnson, M. (1987). The body in the mind: The bodily basis of meaning, imagination, and reason. Chicago: University of Chicago Press.

LeDoux, J.E. (1993). Emotional networks in the brain. In M. Lewis \& J.M. Haviland (Eds.), Handbook of emotions (pp. 109-118). New York: Guilford Press.

Leventhal, H. (1984). A perceptual motor theory of emotion. In L. Berkowitz (Ed.), Advances in experimental social psychology (pp. 117-182). New York: Academic Press.

Mahoney, M. (1991). Human change processes: Notes on the facilitation of personal development. New York: Guilford Press.

Pascual-Leone, J. (1978). Compounds, confounds and models in developmental information processing: A reply to Trabasso and Foellinger. Journal of Experimental Child Psychology, 26, 18-40.

Pascual-Leone, J. (1980). Constructive problems for constructive theories: The current relevance of Piaget's work and a critique of information-processing simulation psychology. In R. Kluwe \& H. Spada (Eds.), Developmental models of thinking (pp. 263296). New York: Academic Press.

Pascual-Leone, J. (1983). Growing into human maturity: Toward a metasubjective theory of adulthood stages. In P. B. Baltes \& O. G. Brim (Eds.), Life-span development and behavior (Vol. 5, pp. 117-156). New York: Academic Press.

Pascual-Leone, J. (1984). Attentional, dialectic and mental effort: Towards an organismic theory of life stages. In M. L. Commons, F. A. Richards, \& G. Armon (Eds.), Beyond formal operations: Late adolescence and adult cognitive development (pp. 182215). New York: Praeger.

Pascual-Leone, J. (1987). Organismic processes for neo-Piagetian theories: A dialectical 
causal account of cognitive development. International Journal of Psychology, 22, 531-570. Also in A. Demetriou (Ed.), The neo-Piagetian theories of cognitive development: Towards an integration (pp. 531-569). Amsterdam: North-Holland.

Pascual-Leone, J. (1989). An organismic process model of Witkin's field-dependenceindependence. In T. Globerson \& T. Zelniker (Eds.), Cognitive style and cognitive development (pp. 36-70). Norwood, NJ: Ablex.

Pascual-Leone, J. (1990a). An essay on wisdom: Toward organismic processes that make it possible. In R. J. Sternberg (Ed.), Wisdom: Its nature, origins, and development (pp. 244-278). New York: Cambridge University Press.

Pascual-Leone, J. (1990b). Reflections on life-span intelligence, consciousness and ego development. In C. Alexander \& E. Langer (Eds.), Higher stages of human development: Perspectives on adult growth (pp. 258-285). New York: Oxford University Press.

Pascual-Leone, J. (1991). Emotions, development and psychotherapy: A dialectical constructivist perspective. In J. Safran \& L. Greenberg (Eds.), Emotion, psychotherapy and change (pp. 302-335). New York: Guilford.

Pascual-Leone, J. (1995). Learning and development as dialectical factors in cognitive growth. Human Development, in press.

Pascual-Leone, J. (1996). Vygotsky, Piaget, and the problems of Plato. Swiss Journal of Psychology, 55, 84-92.

Pascual-Leone, J. (1997). Metasubjective processes: The missing "linguafranca" of cognitive science. In D. Johnson \& C. Erneling (Eds.), The future of the cognitive revolution (pp. 75-101). New York: Oxford University Press.

Pascual-Leone, J. (2000). Mental attention, consciousness and the progressive emergence of wisdom. Journal of Adult Development, 7(4), 241-254.

Pascual-Leone, J., \& Baillargeon, R. (1994). Developmental measurement of mental attention. International Journal of Behavioral Development, 17(1), 161-200.

Pascual-Leone, J., \& Goodman, D. (1979). Intelligence and experience: A Neo-Piagetian approach. Instructional Science, 8, 301-367.

Pascual-Leone, J., \& Irwin, R. (1994). Noncognitive factors in high-road/low-road learning: I. Modes of abstraction in adulthood. Journal of Adult Development, 1(2), 73-89.

Pascual-Leone, J., \& Irwin, R. R. (1998). Abstraction, the will, the self and modes of learning in adulthood. In M. C. Smith \& T. Pourchot, Adult learning and development, Mahwah, NJ: Erlbaum.

Pascual-Leone, J., \& Johnson, J. (1991). The psychological unit and its role in task analysis: A reinterpretation of object permanence. In M. Chandler \& M. Chapman (Eds.), Criteria for competence: Controversies in the assessment of children's abilities (pp. 153-187). Hillsdale, NJ: Erlbaum.

Pascual-Leone, J. \& Johnson, J. (1999). A dialectical constructivist view of representation: Role of mental attention, executives, and symbols. In I. E. Sigel (Ed.), Development of mental representation: Theories and applications (pp. 169-200), Mahwah, NJ: Erlbaum.

Pascual-Leone, J., \& Johnson, J. (2000). Methods of task analysis in cognitive development. York University, Psychology Reports. Unpublished manuscript.

Pascual-Leone, J., \& Morra, S. (1991). Horizontality of water level: A neoPiagetian developmental review. Advances in Child Development and Behaviour, 23, 231-276.

Pennebaker, J. (1990). Opening up: The healing power of confiding in others. New York: Morrow.

Pennebaker, J. W., \& Traue, H. C. (1993). Inhibition and psychosomatic processes. In J. W. Pennebaker \& H. C. Traue (Eds.), Emotion, inhibition and health (pp. 146-163). Gottingen, Germany: Hogrefe \& Huber. 
Perls, F., Hefferline, R., \& Goodman, P. (1951). Gestalt therapy. New York: Dell. Rogers, C. R. (1951). Client-centered therapy. Boston: Houghton-Mifflin.

Scherer, K. R. (1984). On the nature and function of emotion: A component process approach. In K. R. Scherer \& P. Ekman (Eds.), Approaches to emotion (pp. 293-317). Hillsdale, NJ: Erlbaum.

Stern, D. (1985). The interpersonal world of the infant: A view from psychoanalysis and Developmental Psychology. New York: Basic Books.

Stewart, L., \& Pascual-Leone, J. (1992). Mental capacity constraints and the development of moral reasoning. Journal of Experimental Child Psychology, 54, 251-287.

Watson, J., \& Greenberg, L. (1990). Emotion and cognition in experiential therapy: A dialectical-constructivist position. In H. Rosen \& K. Kuelwein (Eds.), Constructing realities: Meaning making perspectives for psychotherapists. San Francisco: Jossey Bass.

Watson, J., \& Rennie, D. (1994). Qualitative analysis of clients subjective experience of significant moments during the exploration of problematic reactions. Journal of Counselling Psychology, 41, 500-509.

Whelton, W., \& Greenberg, L. (2000). The self as a singular multiplicity: A process experiential perspective. In J. Muran, The self in psychotherapy. Washington, DC: APA Press. 